\title{
Risk of hepatitis $C$ virus transmission from patients to surgeons: model based on an unlinked anonymous study of hepatitis $C$ virus prevalence in hospital patients in Glasgow
}

\author{
D Thorburn, K Roy, S O Cameron, J Johnston, S Hutchinson, E A B McCruden, \\ P R Mills, D J Goldberg
}

Gut 2003:52:1333-1338

See end of article for authors' affiliations

Correspondence to: Dr K Roy, Scottish Centre for Infection and Environmental Health, Clifton House, Clifton Place, Glasgow G3 7LN, UK

kirsty.roy@

scieh.csa.scot.nhs.uk

Accepted for publication 16 April 2003

\begin{abstract}
Background: The risk of a surgeon acquiring the hepatitis $\mathrm{C}$ virus $(\mathrm{HCV})$ through occupational exposure is dependant on the prevalence of $\mathrm{HCV}$ infection in the patient population, the probability of a percutaneous injury transmitting $\mathrm{HCV}$, and the incidence of percutaneous injury during surgery.

Aims: To estimate the prevalence of HCV infection in the adult surgical patient population in North Glasgow and thereafter estimate the risk of HCV transmission to surgeons through occupational exposure.

Methods: The prevalence of HCV infection was estimated through the unlinked anonymous testing of samples from male surgical patients, aged 16-49 years, in two North Glasgow hospitals from 1996 to 1997, and adjusting these data for age and sex. Using published estimates of the incidence of percutaneous injury during surgery and percutaneous injury transmitting $\mathrm{HCV}$, the risk of occupational transmission of $\mathrm{HCV}$ to surgeons was then derived.

Results: The estimated prevalence of anti-HCV infection for all adult patients in the two hospitals combined was $1.4 \%$ (cardiothoracic/cardiology $0.8 \%$, orthopaedics/rheumatology $1.4 \%$, general surgery/ENT $2.0 \%$ ). The estimated probability of HCV transmission from an HCV infected patient to an uninfected surgeon was $0.001-0.032 \%$ per annum $(0.035-1.12 \%$ risk over a 35 year professional career).

Conclusions: The risk of an individual surgeon acquiring HCV through occupational exposure is low, even in an area with an extremely high prevalence of HCV among its injecting drug using population. Surgeons however should be encouraged to observe universal precautions and present for assessment after needlestick injuries to protect themselves and their patients from this insidious infection.
\end{abstract}

$\mathrm{H}$ ealth care workers (HCW) are recognised to be at risk of acquiring viral hepatitis through occupational exposure to blood. As all HCWs in the UK are required to undergo vaccination against hepatitis $\mathrm{B}$ virus (HBV) and to show evidence of immunity to infection, the remaining risk to HCWs in the UK is from hepatitis C virus (HCV). As yet, no vaccine is available against HCV and, once infected, most individuals will develop chronic HCV infection, a disease with considerable morbidity and mortality.

HCWs, particularly surgeons, performing exposure prone procedures, where injury to the worker may result in the exposure of the worker's broken skin to the blood of the patient, are likely to be at greatest risk of acquiring HCV through occupational exposure. Although the prevalence of $\mathrm{HCV}$ infection in HCWs, including surgeons, in the UK is recognised to be low, ${ }^{2-4}$ the risk of an individual surgeon acquiring HCV through occupational exposure has not been quantified in the UK. This risk is dependant on the prevalence of HCV infection in the patient population, the probability of a percutaneous injury transmitting $\mathrm{HCV}$, and the incidence of percutaneous injury during surgery. While existing data on the latter two variables are available, ${ }^{5-7}$ the prevalence of HCV among hospital patients undergoing surgery in the UK is unknown.

The aim of this study was to estimate the prevalence of HCV infection in patients undergoing, or with the potential to undergo, surgery in Glasgow and thereafter estimate the probability of surgeons acquiring HCV through occupational exposure.

\section{METHODS}

\section{Setting}

This study was performed in the Greater Glasgow Health Board area, which incorporates the largest city in Scotland with a population of 904000 in 2000. Glasgow has an estimated 7500 current injecting drug users of whom approximately $60 \%$ are infected with HCV. ${ }^{8}$ Patients attending the hospitals (Glasgow Royal Infirmary and Stobhill General Hospital) serving the northern and eastern sectors of the city (population $331000(37 \%)$ ) had been studied as part of an unlinked anonymous programme of human immunodeficiency virus (HIV) surveillance in the West of Scotland. ${ }^{10}$ These hospitals were selected because HIV and injecting drug use were more prevalent in their catchment areas than elsewhere in Glasgow.

\section{Study population and procedure}

Between January 1992 and December 1997, unlinked anonymous HIV surveillance testing was conducted on residual sera from specimens sent for routine urea and electrolyte testing to the laboratories at Glasgow Royal Infirmary and Stobhill General Hospital..$^{10}$ Specimens from male hospital inpatients and outpatients aged 16-49 years who belonged to all clinical specialties, including general practice, were eligible for the study.

Abbreviations: $\mathrm{HCV}$, hepatitis $\mathrm{C}$ virus; $\mathrm{HCW}$, health care worker; $\mathrm{HBV}$, hepatitis B virus; HIV, immunodeficiency virus. 


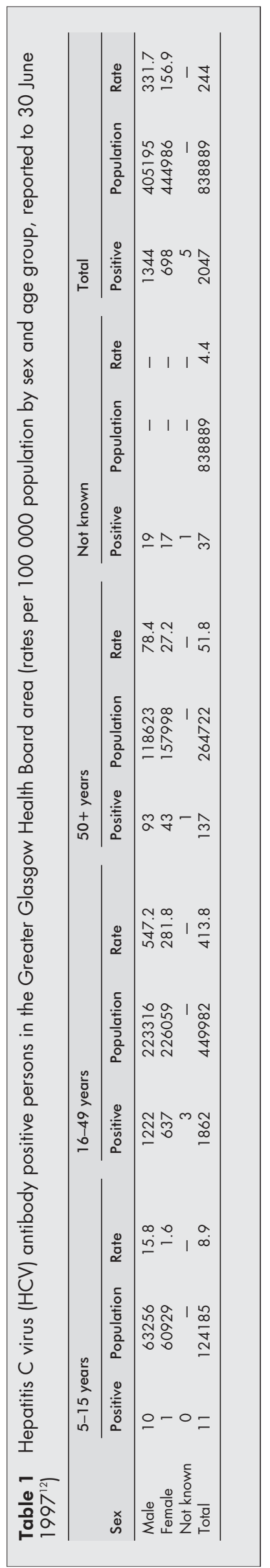

Repeat samples submitted within 90 days of the original sample and samples obtained from patients who objected to anonymous testing or were unable to provide informed consent were excluded. Specimens were anonymised by means of a seven digit code which indicated the year and calendar quarter in which the sample was taken, the hospital and specialty requesting the test, and the patient's age band and sex. ${ }^{10}$

For the current study, samples from patients belonging to three of the eight specialty groupings were eligible for HCV antibody testing. These comprised patients undergoing, or with the potential to undergo, surgery: (a) cardiology/cardiac and other vascular surgery, (b) general surgery/ENT/plastic surgery, and (c) rheumatology/orthopaedics. Testing was restricted to samples taken from patients after October 1996, following the UK Health Departments decision to permit unlinked anonymous HCV testing, in addition to that for HIV, on residual samples.

\section{Samples for testing}

Sera were initially stored by sequential laboratory number at either $4^{\circ} \mathrm{C}$ or $-20^{\circ} \mathrm{C}$ on the day of collection in the biochemistry departments. Following routine biochemical testing, residual sera from the study samples were aliquoted into $2.5 \mathrm{ml}$ vials (Sarstedt Ltd, Leicester, UK), labelled with the unique non-identifying code and stored at $-20^{\circ} \mathrm{C}$. HIV testing was performed at the Regional Virus Laboratory. Samples were thereafter stored at $-20^{\circ} \mathrm{C}$ until $\mathrm{HCV}$ testing was performed.

\section{Hepatitis C tests}

Initially all HCV testing was performed on pools of five sera with a third generation ELISA (ELISA-3; Ortho Diagnostics, Raritan, New Jersey, USA) using methods that have been validated previously. Briefly, $20 \mu \mathrm{l}$ of each of the five sera to be tested were pooled and mixed thoroughly. Fifty microlitres of this pool were transferred into the test plate (the equivalent of $10 \mu \mathrm{l}$ of each serum), diluent was added to a total volume of $200 \mu \mathrm{l}$, and thereafter testing followed the Ortho ELISA-3 protocol. The final dilution of each individual serum in the pool was 1 in 20 compared with individual testing with a 1 in 11 dilution. The five sera in any reactive pool were then tested individually using the same ELISA-3 (Ortho Diagnostics). Any samples reactive on individual ELISA-3 testing underwent confirmatory testing using a different third generation ELISA (Sanofi Ltd., Northumberland, UK). Any samples that had discrepant results on individual testing by third generation ELISA underwent confirmatory testing by RIBA-3 (Ortho Diagnostics).

Samples were considered positive if they were reactive on individual testing with both third generation ELISAs or if both the initial ELISA-3 and confirmatory RIBA-3 testing were positive.

\section{Modelling of risk of HCV infection though percutaneous injury}

The annual risk of a surgeon acquiring HCV infection through percutaneous injury is the product of three key variables: (i) the probability of the patient being infected (HCV prevalence), (ii) the probability of a percutaneous injury from an HCV infected patient transmitting HCV, and (iii) the number of percutaneous needlestick injuries the surgeon experiences.

\section{Estimating HCV prevalence}

Because HCV testing was performed on specimens from adult males aged between 16 and 49 years, adjustments were required to estimate HCV prevalence among all adults undergoing, or eligible to undergo, surgery. For each of the three different types of surgery, and for all types combined, calculations were performed in four stages. The model was based on 
Table 2 Observed hepatitis C virus (HCV) antibody prevalence for 16-49 year old males undergoing, or eligible to undergo, surgery

\begin{tabular}{|c|c|c|c|c|c|c|c|c|c|}
\hline \multirow[b]{2}{*}{ Specialty group } & \multicolumn{3}{|c|}{ Glasgow Royal Infirmary (16-49 years) } & \multicolumn{3}{|c|}{ Stobhill General Hospital (16-49 years) } & \multicolumn{3}{|l|}{ Total } \\
\hline & $\begin{array}{l}\text { Tested } \\
\left(\mathrm{N}^{m}\right)\end{array}$ & $\underset{\left(\mathrm{H}^{\mathrm{m}}\right)}{\mathrm{HCV} \text { positive }}$ & $\begin{array}{l}\text { Prevalence } \\
(\%)\end{array}$ & $\begin{array}{l}\text { Tested } \\
\left(\mathrm{N}^{m}\right)\end{array}$ & $\underset{\left(\mathrm{H}^{\mathrm{m}}\right)}{\mathrm{HCV} \text { positive }}$ & $\begin{array}{l}\text { Prevalence } \\
(\%)\end{array}$ & $\begin{array}{l}\text { Tested } \\
\left(\mathrm{N}^{\mathrm{m}}\right)\end{array}$ & $\begin{array}{l}\text { HCV positive } \\
\left(\mathrm{H}^{\mathrm{m}}\right)\end{array}$ & $\begin{array}{l}\text { Prevalence } \\
(\%)\end{array}$ \\
\hline $\begin{array}{l}\text { Cardiothoracic/ } \\
\text { cardiology }\end{array}$ & 632 & 15 & 2.4 & 253 & 4 & 1.6 & 885 & 19 & 2.1 \\
\hline $\begin{array}{l}\text { Orthopaedics/ } \\
\text { rheumatology }\end{array}$ & 647 & 20 & 3.1 & 320 & 17 & 5.3 & 967 & 37 & 3.8 \\
\hline $\begin{array}{l}\text { General } \\
\text { surgery/ENT }\end{array}$ & 679 & 43 & 6.3 & 171 & 4 & 2.3 & 850 & 47 & $5.5 t$ \\
\hline Total & 1958 & 78 & 4.0 & 744 & 25 & $3.4^{*}$ & 2702 & 103 & 3.8 \\
\hline
\end{tabular}

$\mathrm{H}^{\mathrm{m}}$, number of $\mathrm{HCV}$ antibody positive males aged 16-49 years; $\mathrm{N}^{\mathrm{m}}$, number of males aged 16-49 years $\mathrm{HCV}$ antibody tested.

*Glasgow Royal Infirmary versus Stobhill General Hospital, NS.

tGeneral surgery versus orthopaedics, $\mathrm{p}=0.002$

that previously used by some of the authors to estimate the risk of surgeons acquiring HIV through occupational exposure. ${ }^{11}$

Stage 1

The prevalence of HCV antibodies among 16-49 year old males was calculated using the following formula:

$$
\mathrm{P}^{16-49 \text { males }}=\mathrm{H}^{\mathrm{m}} / \mathrm{N}^{\mathrm{m}}
$$

where $\mathrm{H}^{\mathrm{m}}=$ number of $\mathrm{HCV}$ antibody positive males aged 16-49 years and $\mathrm{N}^{\mathrm{m}}=$ number of tested males aged 16-49 years.

\section{Stage 2}

The estimated HCV prevalence among all adults aged 16-49 years was:

$$
P^{16-49}=P^{16-49 \text { males }}+\left(Y \times P^{16-49 \text { males }}\right) / 2
$$

where $\mathrm{Y}=$ factor used to account for the HCV prevalence among all adults aged 16-49. As of 30 June 1997, the rates per 100000 population of female and male HCV antibody positive diagnosis, aged 16-49 years, from Glasgow were 281.8 and 547.2, respectively (table 1). ${ }^{12}$ Assuming that the rate ratio of 34:66 (1:1.9) was reflected in the surgical patient population aged 16-49 years, the prevalence in the female population (16-49 years) would be $51.5 \%$ of that seen in the male population ( $16-49$ years). Thus $\mathrm{Y}=0.515$.

\section{Stage 3}

The estimated prevalence among adults aged over 50 years was calculated using the formula:

$$
\mathrm{P}^{50+}=\mathrm{Z} \times \mathrm{P}^{16-49}
$$

where $\mathrm{Z}=$ the factor used to account for the difference in the prevalence there would be among the older population. As of 30 June 1997, the rates per 100000 population HCV antibody positive diagnosis, aged $50+$ and $16-49$ years, were 51.8 and 413.8 (table 1). Assuming that the resulting rate ratio of $0.11: 0.89(1: 8)$ was reflected in the surgical patient population, the prevalence in the older age group would be one eighth of that seen in the younger population. Thus $Z=0.125$ $(1 / 8)$

\section{Stage 4}

The estimated HCV prevalence among all adults was calculated using the following formula:

$$
\mathrm{P}^{\text {aduls }}=\mathrm{P}^{16-49}+\left(\alpha \times \mathrm{P}^{50+}\right) / 1+\alpha
$$

where $\alpha=$ the factor used to account for the difference between the numbers of patients aged 16-49 years and 50+ years undergoing, or eligible to undergo, surgery. For adults undergoing surgery during 1997, there were 1.5 persons aged $50+$ years for every individual aged 16-49 years (Information and Statistics Division, NHS, Scotland). Thus $\alpha=1.5$.

\section{Example}

For example, the estimated HCV prevalence for all adults ( $>16$ years) in all three surgical specialties and in both hospitals combined is calculated as follows:

\section{Stage 1 (table 2)}

$$
P^{16-49 \text { moles }}=H^{m} / N^{m}=103 / 2702=3.8 \%
$$

Stage 2 (table 4)

$$
\begin{aligned}
& P^{16-49}=P^{16-49}{ }^{\text {males }}+\left(Y \times P^{16-49} \text { males }\right) / 2=3.8+(0.515 \times 3.8) \% / 2 \\
& =2.9 \%
\end{aligned}
$$

Stage 3

$$
P^{50+}=Z \times P^{16-49}=0.125 \times 2.9 \%=0.36 \%
$$

Stage 4

$$
\mathrm{P}^{\text {adults }}=\mathrm{P}^{16-49}+\left(\alpha \times \mathrm{P}^{50+}\right) / 1+\alpha=2.9+(1.5 \times 0.36) \% / 1+1.5=
$$$$
1.4 \%
$$

Probability of percutaneous injury resulting in $\mathrm{HCV}$ infection

The average incidence of anti-HCV seroconversion after unintentional needlestick or sharps exposure from an HCV antibody positive source is $1.8 \%$ (range $0-7 \%$ ). ${ }^{7}$ The rate accounts for a majority $(75-80 \%)$ of anti-HCV positive persons being viraemic and thus infectious.

Percutaneous injuries included in these studies have largely resulted from hollow bore phlebotomy needles without the protective effect of gloves. It is likely that the risk of transmission of HCV after percutaneous exposure relates to the volume of infected blood, as has been observed with HIV. ${ }^{13}$ Two in vitro studies have reported a comparable $86 \%$ reduction in the volume of inoculum when a solid suture needle causes injury through a single layer of glove material. ${ }^{14}{ }^{15}$ For the purposes of this study, we estimated that the risk of HCV transmission in the surgical setting, where gloves are universally worn and needlestick injuries are mostly from suture needles, would be reduced 10 -fold to $0.18 \%$.

Number of percutaneous injuries sustained annually by a surgeon

This number can vary considerably at an individual, specialty, and geographical level. Accordingly, a range of numbers ( 1,3 , 
Table 3 Observed hepatitis $\mathrm{C}$ virus (HCV) antibody prevalence rates for male 16-49 year olds in five year age bands undergoing, or eligible to undergo, surgery

\begin{tabular}{|c|c|c|c|c|}
\hline & $\begin{array}{l}\text { Cardiothoracic/ } \\
\text { cardiology }\end{array}$ & $\begin{array}{l}\text { Orthopaedics/ } \\
\text { rheumatology }\end{array}$ & $\begin{array}{l}\text { General } \\
\text { surgery/ENT }\end{array}$ & Total (prevalence \%) \\
\hline \multicolumn{5}{|c|}{$16-19$ years } \\
\hline Tested & 11 & 37 & 67 & 115 \\
\hline Positive & 0 & 0 & 1 & $1(0.9 \%)$ \\
\hline \multicolumn{5}{|c|}{$20-24$ years } \\
\hline Tested & 30 & 55 & 74 & 159 \\
\hline Positive & 0 & 1 & 3 & $4(2.5 \%)$ \\
\hline \multicolumn{5}{|c|}{$25-29$ years } \\
\hline Tested & 57 & 120 & 92 & 269 \\
\hline Positive & 3 & 7 & 9 & $19(7.1 \%)$ \\
\hline \multicolumn{5}{|c|}{ 30-34 years } \\
\hline Tested & 81 & 150 & 135 & 366 \\
\hline Positive & 7 & 15 & 22 & 44 (12.0\%) \\
\hline \multicolumn{5}{|c|}{$35-39$ years } \\
\hline Tested & 160 & 175 & 145 & 480 \\
\hline Positive & 5 & 2 & 5 & $12(2.5 \%)$ \\
\hline \multicolumn{5}{|c|}{$40-44$ years } \\
\hline Tested & 248 & 226 & 166 & 640 \\
\hline Positive & 3 & 10 & 5 & $18(2.8 \%)$ \\
\hline \multicolumn{5}{|c|}{$45-49$ years } \\
\hline Tested & 298 & 204 & 174 & 676 \\
\hline Positive & 1 & 2 & 2 & $5(0.7 \%)$ \\
\hline
\end{tabular}

and 9 per year), which are compatible with those observed in European and North American investigations of injuries sustained by surgeons during the 1990s, are incorporated into the analysis. ${ }^{56}$

\section{Ethics}

Ethics approval for unlinked anonymous testing was obtained from the NHS Trust research ethics committees in both Glasgow hospitals. Statistical analysis of the data was performed

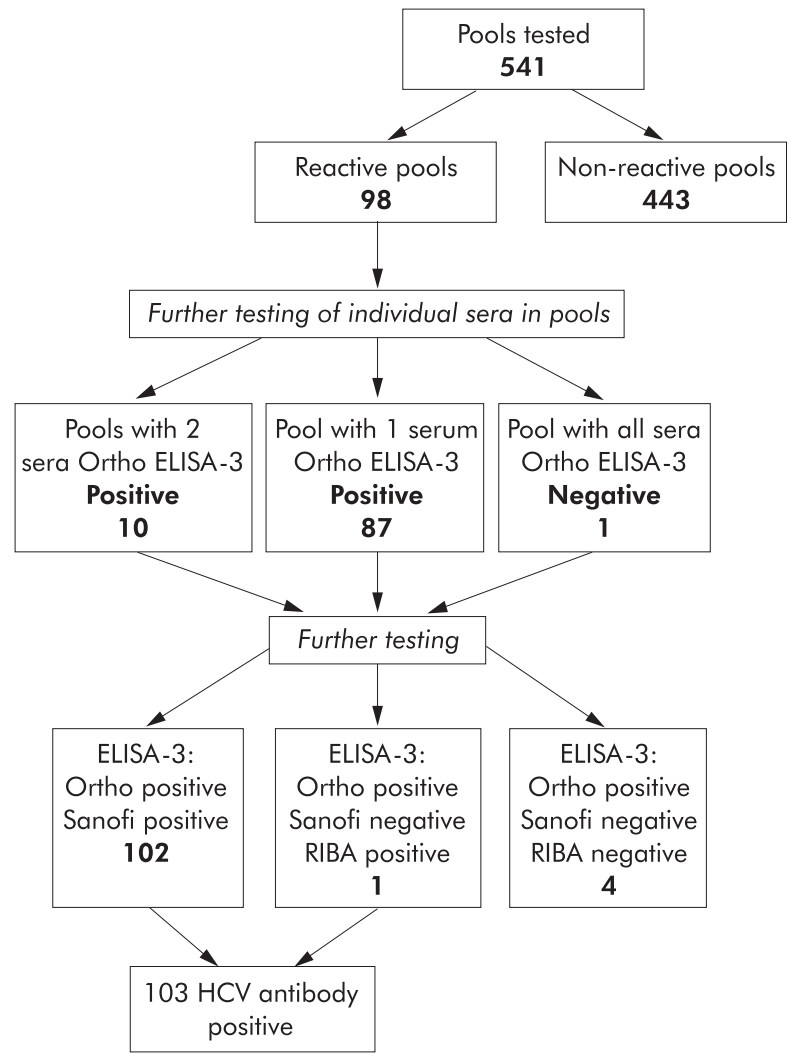

Figure 1 Summary of testing 2702 hospital inpatient and outpatient sera for antibodies to hepatitis $\mathrm{C}$ virus (HCV) by Ortho ELISA-3 in pools of five. using the $\chi^{2}$ test and, where indicated, Fisher's exact test using SigmaStat (SPSS Science Software UK Ltd, Birmingham, UK).

\section{RESULTS}

HCV prevalence for males aged 16-49 years (tables 2, 3)

Figure 1 summarises the results of pooled HCV antibody testing and confirmatory testing of samples reactive on individual testing. The overall prevalence of HCV antibodies was 3.8\% (103/2702). Observed prevalence rates among males aged 16-49 years varied from $1.6 \%$ among cardiothoracic/ cardiology patients at Stobhill General Hospital to 6.3\% among general surgery/ENT patients at Glasgow Royal Infirmary (table 2$)$. No statistically significant $(\mathrm{p}<0.05)$ difference in overall prevalence was observed between the hospitals; however, there was a significant difference in the prevalence observed among specialty groupings $(p=0.002)$.

Table 3 summarises the prevalence of HCV antibodies according to age band of those tested. A significant difference was observed in anti-HCV prevalence among different age groups $(\mathrm{p}<0.001)$ (table 3$)$; the highest prevalences were observed in the 25-29 year and 30-34 year age bands $(7.1 \%$ and $12.0 \%$, respectively). There were no significant differences in the prevalence of anti-HCV among specialties in any of the age bands.

\section{HCV prevalence (estimated) (tables 4, 5)}

Estimated rates for all adult men and women in the two hospitals combined are shown by specialty grouping in table 4 . Prevalences of $0.8 \%, 1.4 \%$, and $2.0 \%$ were estimated among cardiothoracic/cardiology, orthopaedics/rheumatology, and general surgery/ENT patients, respectively; for all patients in all specialty groupings the estimated prevalence was $1.4 \%$.

Estimated rates for each five year age band for all adults, displayed in table 5, were derived from the observed prevalences among the tested male patients (table 3 ) using the equation in stage 2 . Peak prevalence rates were observed in the $25-29$ year and $30-34$ year age bands $(5.4 \%$ and $9.1 \%$, respectively).

\section{Annual probability of a surgeon acquiring HCV}

A range of probabilities of a surgeon acquiring HCV annually is presented within the matrix (table 6). Probabilities are based on a scale of anti-HCV prevalence from $0.8 \%$ to $2 \%$ and 
Table 4 Estimated hepatitis $\mathrm{C}$ virus $(\mathrm{HCV})$ antibody prevalence rates for all adults undergoing, or eligible to undergo, surgery (Glasgow Royal Infirmary and Stobhill General Hospital combined)

\begin{tabular}{lllll}
\hline Specialty Group & $\begin{array}{l}\text { Prevalence in males } \\
16-49\left(\mathbf{P}^{16-49} \text { males }\right.\end{array}$ & $\begin{array}{l}\text { Prevalence in } \\
16-49\left(\mathbf{P}^{16-49}\right)\end{array}$ & $\begin{array}{l}\text { Prevalence in } \\
50+\left(\mathbf{P}^{50+}\right)\end{array}$ & $\begin{array}{l}\text { Prevalence in all } \\
\text { adults }\left(\mathbf{P}^{\text {adults }}\right)\end{array}$ \\
\hline Cardiothoracic/cardiology & $2.1 \%$ & $1.6 \%$ & $0.2 \%$ & $0.8 \%$ \\
Orthopaedics/rheumatology & $3.8 \%$ & $2.9 \%$ & $0.4 \%$ & $1.4 \%$ \\
General surgery/ENT & $5.5 \%$ & $4.2 \%$ & $0.5 \%$ & $2.0 \%$ \\
Total & $3.8 \%$ & $2.9 \%$ & $0.4 \%$ & $1.4 \%$ \\
\hline
\end{tabular}

Table 5 Estimated hepatitis $\mathrm{C}$ virus $(\mathrm{HCV})$ antibody prevalence rates for adults undergoing, or eligible to undergo, surgery analysed in five year age bands (Glasgow Royal Infirmary and Stobhill General Hospital combined)

\begin{tabular}{lll}
\hline Age band (years) & Males only (observed) & All adults (estimated) \\
\hline $16-19$ & $0.9 \%$ & $0.7 \%$ \\
$20-24$ & $2.5 \%$ & $1.9 \%$ \\
$25-29$ & $7.1 \%$ & $5.4 \%$ \\
$30-34$ & $12.0 \%$ & $9.1 \%$ \\
$35-39$ & $2.5 \%$ & $1.9 \%$ \\
$40-44$ & $2.8 \%$ & $2.1 \%$ \\
$45-49$ & $0.7 \%$ & $0.5 \%$ \\
\hline
\end{tabular}

on the number of sustained percutaneous injuries from one to nine (in multiples of three). The three shaded areas highlight the probabilities based on the estimated prevalences calculated for the three specialty groupings (see table 4). For surgeons performing general surgery and sustaining, for example, three percutaneous injuries in 12 months, the annual risk of acquiring HCV would be 1.1 in 10000 (that is, 0.02 (HCV prevalence) $\times 3$ (No of percutaneous injuries per annum) $\times 0.0018$ (incidence of HCV seroconversion after needlestick injury)). The corresponding annual risks for those undertaking cardiothoracic and orthopaedic surgery who sustained three injuries would be 0.4 and 0.8 in 10 000, respectively.

\section{DISCUSSION}

The estimated annual probability of a surgeon acquiring HCV ranged from $0.001 \%$ (one injury and HCV prevalence of $0.8 \%$ ) to $0.032 \%$ (nine injuries and HCV prevalence of $2 \%$ ), depending on the type of surgery performed and the number of needlestick injuries sustained. If the above range of probability applies consistently across a 35 year working span, the occupational lifetime chance of a surgeon becoming infected with HCV in this area, with a high injecting drug use prevalence and high HCV prevalence among injectors, would range from $0.035 \%$ ( 1 in 2857 ) to $1.12 \%$ ( 1 in 89 ). These low rates, even at the improbable upper end of the spectrum, are consistent with a maximum 1.4\% occupational lifetime risk, which was generated by the same investigators through an unlinked anonymous HCV testing survey of surgeons in Glasgow; only 1 of 438 surgeons had antibodies to HCV detectable and the source and timing of his/her infection was unknown. ${ }^{4}$

While the risk of HCV transmission from patient to surgeon is low, both the observed and estimated HCV prevalences among surgical patients indicate that surgeons working in areas of high injecting drug use prevalence and high HCV prevalence among injectors will frequently operate on HCV infected patients (an estimated 1.4\% of all surgical patients). Indeed, in Glasgow, the prevalence of HCV among surgical patients is greater than the estimated HCV prevalence of $0.9 \%$ in the city's overall population (unpublished data, SCIEH) Data on the prevalence of HCV among surgical patients elsewhere in the UK do not exist but our findings are consistent with reports from the USA where the prevalence of HCV in such patients exceeded those in the corresponding general populations to which they belong. ${ }^{16-19}$ These observations may be explained by the over representation of intravenous drug users among surgical populations due to the predilection for surgical interventions following injecting related trauma, abscesses, and vascular events..$^{20}$ In addition, hospitalised surgical patients may have had medical interventions requiring blood transfusions before blood donor screening for HCV was introduced

The study model is dependent on local HCV prevalence estimates among patients undergoing surgery and thus the risk probabilities generated by it are unlikely to be appropriate for surgeons practising in areas with different prevalences of injecting drug use and HCV among their injecting drug user populations. The HCV prevalence among all adult patients undergoing, or with the potential to undergo, surgery was

Table 6 Estimated annual probability of a surgeon acquiring hepatitis $\mathrm{C}$ virus (HCV) infection through percutaneous injury (rate per 10 000)

\begin{tabular}{|c|c|c|c|c|c|}
\hline & & \multicolumn{4}{|c|}{ Annual number of percutaneous injuries } \\
\hline & & 1 & 3 & 6 & 9 \\
\hline Prevalence of $\mathrm{HCV}$ & 0.8 & 0.1 & 0.4 & 0.9 & 1.3 \\
\hline among patient & 1 & 0.2 & 0.5 & 1.1 & 1.6 \\
\hline populations (\%) & 1.2 & 0.2 & 0.6 & 1.3 & 1.9 \\
\hline & 1.4 & 0.2 & 0.8 & 1.5 & 2.3 \\
\hline & 1.6 & 0.3 & 0.9 & 1.7 & 2.6 \\
\hline & 1.8 & 0.3 & 1.0 & 1.9 & 2.9 \\
\hline & 2 & 0.4 & 1.1 & 2.2 & 3.2 \\
\hline
\end{tabular}

Probabilities are based on a scale of anti-HCV prevalence from $0.8 \%$ to $2 \%$ and on the number of sustained percutaneous injuries from one to nine (in multiples of three). The three shaded areas highlight the probabilities based on the estimated prevalences calculated for the three specialty groupings multiples of three). The three shaded areas highlight the probabilities based on the estimated prevalences calculated for the three specialty groupings
$(0.8 \%$ cardiothoracic/cardiology, $1.4 \%$ orthopaedics/rheumatology, $2.0 \%$ general surgery/ENT) and for all patients in all specialty groupings (1.4\%). 
derived through the application of weightings, based on age and sex distributions of diagnosed HCV antibody positive cases in the Greater Glasgow Health Board area, ${ }^{12}$ to observed prevalence data on male patients aged 16-49 years. These distributions however may not reflect those for all (diagnosed and undiagnosed) HCV infections in the general populations or, more relevantly, among surgical patients.

The model is also dependent on the incidence of needlestick injury during surgery, the estimates for which emanated from literature relevant to surgical practice in North America and Europe. It is recognised that the incidence of percutaneous exposure varies appreciably among individuals, specialities, and procedures. ${ }^{21}$ In a prospective study, performed in operating theatres of Glasgow Royal Infirmary (one of the hospitals included in this study), the incidence of percutaneous exposure was reported to be 15.5 per operator per 1000 operations..$^{22}$ This equates to four to five needlestick injuries per year per surgeon, if 250-350 surgical procedures are being performed, a rate which falls within the range included in our model.

To date in the UK, there are no published reports of HCV seroconversions in HCWs following occupational injuries. ${ }^{23}$ The absence of reported cases among surgeons likely reflects surgeons' reluctance to engage in a risk assessment with an occupational health specialist following injury with only an estimated 1 in 20 needlestick injuries reported. ${ }^{24}$ Despite the risk of surgeons acquiring HCV from patients being extremely low, those infected, by whatever means, pose a risk to their patients. Several instances of surgeon to patient transmission have now been reported in the UK. ${ }^{25}$ Accordingly, the UK Departments of Health introduced guidelines in July 2002 to exclude known HCV infected HCWs from undertaking exposure prone procedures until a sustained virological response to antiviral therapy has been documented. ${ }^{26}$ Staff performing exposure prone procedures will not be required to undergo mandatory testing but will be expected to discuss, with occupational health staff, the need for testing if they know or suspect themselves to be infected with HCV.

The risk assessment findings, generated through the use of data, applicable to one of the highest HCV prevalence areas in the UK, should reassure surgeons that the chances of a suture needlestick injury resulting in HCV acquisition are extremely low. Nevertheless, surgeons will frequently operate on known and unknown HCV infected persons. In the absence of a vaccine against $\mathrm{HCV}$, it is essential that the risk of infection in the healthcare setting should be minimised through the observance of universal precautions and the development of safer surgical techniques. ${ }^{6}$ Furthermore, as early detection and treatment of acute HCV infection after needlestick exposure is associated with sustained viral clearance rates of over $90 \%,{ }^{27}$ the benefits of surgeons presenting to occupational health departments for HCV testing after sustaining percutaneous injuries are compelling. In so doing, both surgeons and their patients can be protected against the effects of this insidious infection.

\section{ACKNOWLEDGEMENTS}

The authors would like to thank Mrs Linda McDonald and Mrs Elaine Murray for identifying, pooling, and testing the sera. In addition, we would like to thank Louise Shaw and Glenn Codere at the Scottish Centre for Infection and Environmental Health who are responsible for the collection of data for, and the management of, the National HCV Register.

\section{Authors' affiliations}

D Thorburn, P R Mills, Gastroenterology Unit, Gartnavel General Hospital, Glasgow, UK
K Roy, S Hutchinson, D J Goldberg, Scottish Centre for Infection and Environmental Health, Clifton House, Glasgow, UK

S O Cameron, Regional Virus Laboratory, Gartnavel General Hospital, Glasgow, UK

J Johnston, Department of Clinical Biochemistry, Glasgow Royal Infirmary, Glasgow UK

E A B McCruden, Division of Virology, IBLS, University of Glasgow, Glasgow, UK

\section{REFERENCES}

I Niederau C, Lange S, Heintges T, et al. Prognosis of chronic hepatitis C: Results of a large, prospective cohort study. Hepatology

1998;28:1687-95.

2 Zuckerman J, Clewley G, Griffiths P, et al. Prevalence of hepatitis C antibodies in clinical health-care setting. Lancet 1994;343:1618-20.

3 Neal KR, Dornan J, Irving WL. Prevalence of hepatitis $C$ antibodies among healthcare workers of two teaching hospitals. Who is at risk? BM 1997:314:179-80.

4 Thorburn D, Dundas D, McCruden EAB, et al. A study of hepatitis $C$ prevalence in healthcare workers in the West of Scotland. Gut 2001;48: 116-120.

5 Lowenfals A, Mehta V, Levi D, et al. Reduced frequency of percutaneous injuries in surgeons: 1993 versus 1988. AIDS 1995;9:199-202.

6 Guidance for Clinical Health Care Workers: Protection against Infection with Bloodborne Viruses. UK Health Departments, March 1998.

7 Centers for Disease Control. Recommendations for prevention and control of hepatitis C virus (HCV) infection and HCV-related chronic disease. MMWR Morb Mortal Wkly Rep 1998;47:1-39.

8 Hay G, McKeganey N, Hutchinson S. Estimating the National and Local Prevalence of Drug Misuse in Scotland. The Scottish Executive, Executive Report, September 2001.

9 Goldberg D, Burns S, Taylor A, et al. Trends in HCV prevalence among injecting drug users in Glasgow and Edinburgh during the era of needle/syringe exchange. Scand J Infect Dis 2001;33:457-61.

10 Johnston J, Cameron S, Stewart M, et al. Unlinked anonymous HIV study of hospital patients and general practice attenders in Glasgow, 1991-1997. J Clin Pathol 2000;53:117-121.

11 Goldberg D, Johnston J, Cameron S, et al. Risk of HIV transmission from patients to surgeons in the era of post-exposure prophylaxis. J Hosp Infect 2000;44:99-105

12 Surveillance of known hepatitis $C$ antibody positive cases in Scotland: Results to 30 June 1999. SCIEH Weekly Report 1999;33:29.

13 Cardo DM, Culver DH, Cisielski CA, et al. A case-control study of HIV seroconversion in healthcare workers after percutaneous exposure. $\mathrm{N}$ Engl J Med 1997;337:1485-90.

14 Mast S, Woolwine J, Geberding J. Efficacy of gloves in reducing blood volumes transferred during simulated needlestick injury. J Infect Dis 1993; 169:1589-92.

15 Bennet NT, Howard RJ. Quantity of blood inoculated in a needlestick injury from suture needles. J Am Coll Surg 1994;178:107-10.

16 Kaplan AJ, Zone-Smith LK, Hannegan C, et al. The prevalence of hepatitis $C$ in a regional level I trauma center population. J Trauma 1992;33:126-9.

17 Montecalvo MA, Lee MS, DePalma $\mathrm{H}$, et al. Seroprevalence of immunodeficiency virus- 1 , hepatitis $B$ virus, and hepatitis $C$ virus in patients having maior surgery. Infect Control Hosp Epidemiol patients having maior

18 Simonian $P$, Gilbert $M$, Trumble T. Incidence of hepatitis $C$ in patients requiring orthopaedic surgery. J Bone Joint Surg (Br) 1995;77B:971-4

19 Austin GE, Jensen B, Leete J, et al. Prevalence of hepatitis $C$ virus seropositivity among hospitalised US veterans. Am J Med Sci 2000:319:353-9.

20 Stone $\mathbf{M H}$, Stone DH, MacGregor HA. Intravenous drug misusers presenting to the accident and emergency department of a large teaching hospital. A failure of clinical management? Scot Med J 1989;34:428-30.

21 Chamberland ME, Ciesielski CA, Howard RJ, et al. Occupational risk of infection with Human Immunodeficiency Virus. Surg Clin North Am $1995: 75: 1057-70$

22 Camilleri, AE, Murray S, Imrie CW. Needlestick injury in surgeons: what is the incidence? J R Coll Surg Edinb 1991;36:317-18.

23 Evans B, Duggan W, Baker J, et al. Exposure of healthcare workers in England, Wales and Northern Ireland to bloodbourne viruses between July1997 and June 2000: analysis of surveillance data. BM 2001;322:397-8.

24 Nash GF, Goon P. Current attitudes to surgical needlestick injuries. Ann $R$ Coll Surg Engl 2000;82:236-7.

25 Duckworth GJ, Heptonstall J, Aitken C. Transmission of hepatitis C virus from a surgeon to a patient. Comm Dis Pub Health 1999;2:188-92.

26 UK Department of Health. Hepatitis C Infected Health Care Workers. Health Service Circular 2002/010 (http://www.doh.gov.uk/coinh.htm).

27 Piasecki BA, Reddy KR, Chang K-M. Acute hepatitis C: to treat or not to treat? Hepatology 2002;35:1538-40 